\title{
Angular and energy dependence of ion bombardment of Mo/Si multilayers
}

\author{
Voorma, H.J.; Louis, E.; Bijkerk, F.; Abdali, Salim
}

Published in:

Journal of Applied Physics

Link to article, DOI:

10.1063/1.365992

Publication date:

1997

Document Version

Publisher's PDF, also known as Version of record

Link back to DTU Orbit

Citation (APA):

Voorma, H. J., Louis, E., Bijkerk, F., \& Abdali, S. (1997). Angular and energy dependence of ion bombardment of Mo/Si multilayers. Journal of Applied Physics, 82(4), 1876-1881. https://doi.org/10.1063/1.365992

\section{General rights}

Copyright and moral rights for the publications made accessible in the public portal are retained by the authors and/or other copyright owners and it is a condition of accessing publications that users recognise and abide by the legal requirements associated with these rights.

- Users may download and print one copy of any publication from the public portal for the purpose of private study or research.

- You may not further distribute the material or use it for any profit-making activity or commercial gain

- You may freely distribute the URL identifying the publication in the public portal

If you believe that this document breaches copyright please contact us providing details, and we will remove access to the work immediately and investigate your claim. 


\title{
Angular and energy dependence of ion bombardment of Mo/Si multilayers
}

\author{
H.-J. Voorma, ${ }^{a}$ E. Louis, and F. Bijkerk \\ FOM-Institute for Plasma Physics Rijnhuizen, Edisonbaan 14, 3439 MN Nieuwegein, The Netherlands \\ S. Abdali \\ Danish Space Research Institute, Juliane Maries Vej 30, DK-2100 Copenhagen, Denmark
}

(Received 10 March 1997; accepted for publication 13 May 1997)

\begin{abstract}
The process of ion bombardment is investigated for the fabrication of $\mathrm{Mo} / \mathrm{Si}$ multilayer $\mathrm{x}$-ray mirrors using $e$-beam evaporation. The ion treatment is applied immediately after deposition of each of the Si layers to smoothen the layers by removing an additional thickness of the Si layer. In this study the parameters of $\mathrm{Kr}^{+}$ion bombardment have been optimized within the energy range 300 $\mathrm{eV}-2 \mathrm{keV}$ and an angular range between $20^{\circ}$ and $50^{\circ}$. The optical performance of the $\mathrm{Mo} / \mathrm{Si}$ multilayers is determined by absolute measurements of the near-normal-incidence reflectivity at $14.4 \mathrm{~nm}$ wavelength. The multilayer structures are analyzed further with small-angle reflectivity measurements using both specular reflectivity and diffuse $x$-ray scattering. The optimal smoothening parameters are obtained by determining the effect of ion bombardment on the interface roughness of the Si layer. The optimal conditions are found to be $2 \mathrm{keV}$ at $50^{\circ}$ angle of incidence with respect to the surface. These settings result in $47 \%$ reflectivity at $85^{\circ}(\lambda=14.4 \mathrm{~nm})$ for a 16-period $\mathrm{Mo} / \mathrm{Si}$ multilayer mirror, corresponding to an interface roughness of $0.21 \mathrm{~nm} \mathrm{rms}$. Analysis shows that the interface roughness is determined by ion induced viscous flow, an effect which increases with ion energy as well as angle of incidence. In order to determine the effect of intermixing of the $\mathrm{Si}$ and Mo atoms, the penetration depth of the $\mathrm{Kr}^{+}$ions is calculated as a function of ion energy and angle of incidence. Furthermore, the angular dependence of the etch yield, obtained from the in situ reflectivity measurements, is investigated in order o determine the optimal ion beam parameters for the production of multilayer mirrors on curved substrates. (C) 1997 American Institute of Physics. [S0021-8979(97)04716-6]
\end{abstract}

\section{INTRODUCTION}

Roughness of the interfaces determines to a considerable extent the reflectivity of multilayer soft $x$-ray mirrors. If the mirrors are produced with e-beam evaporation, additional techniques, such as ion bombardment, can be used to reduce the interface roughness. The ability to use these techniques rather independently of the primary deposition process, is considered to be an advantage over other deposition techniques such as sputter deposition. Optimization of the deposition process as well as modification of the interface roughness by ion bombardment can be performed independently. A similar combination of two separate processes for deposition and modification of the interfaces is applied in dual ion-beam deposition. ${ }^{1,2}$

Multilayer mirrors produced with $e$-beam deposition in combination with ion bombardment show a reduced interface roughness. ${ }^{3,4}$ During the last few years several types of ions have been investigated $\left(\mathrm{Ar}^{+}, \mathrm{Kr}^{+}\right){ }^{5,6}$ Other ions, such as $\mathrm{H}^{+}$and $\mathrm{N}^{+}$, have been used to modify the chemical composition of the layers. ${ }^{7}$

For the fabrication of $\mathrm{Mo} / \mathrm{Si}$ multilayers, $\mathrm{Kr}^{+}$has been found to result in a better reduction of the interface roughness compared to $\mathrm{Ar}^{+} .{ }^{6}$ An optimal ion energy of $300 \mathrm{eV}$ has been found by studying the deposition and ion beam modification of single Mo and Si films. ${ }^{8}$ In Ref. 8, however, relatively thick layers (over $10 \mathrm{~nm}$ ) were used compared to the usual layer thickness in a Mo/Si multilayer (below $5 \mathrm{~nm}$ ).

${ }^{a}$ Current address: ASM-lithography, Veldhoven. Electronic mail: voorma@ rijnh.inl
Such thick layers are not preferred because the morphology of the layers can change with the thickness deposited. Such a morphology, which changes with increasing thickness, has been reported for $\mathrm{Cu}$ as early as $1954^{9}$ and later for many other materials, such as $\mathrm{Mo}^{10}$ and $\mathrm{Si}^{11}$ Moreover, in earlier studies, such as Ref. 8, the angle of incidence has not been optimized.

In order to explain the formation of interface roughness of a layer, the growth of that layer is modelled. In other studies on layer growth, the roughening term was found to consist of stochastic roughening by the deposition of atoms. ${ }^{3}$ The smoothening effects were identified as diffusion and viscous flow. ${ }^{12}$ Also, studies have been performed for the modification of bulk materials with ion bombardment, such as $\mathrm{SiO}_{2}$, in which it was found that roughening is caused by the removal of atoms. ${ }^{13,14}$

In this work the angular as well as the energy dependence of ion bombardment is studied systematically over a wide range, in order to optimize the ion beam parameters with layer thicknesses suitable for practical application, first of all to the reflection of $13.5 \mathrm{~nm}$ radiation at near-normal incidence. Besides the smoothening and roughening processes, several other processes might influence the interface roughness of the multilayers. Therefore, the etch yield and the effect of intermixing by ions that penetrate through the layer are investigated, both as a function of ion energy and angle of incidence. The angular dependence of the etch yield is important when multilayer coatings are produced on curved substrates for optical systems, because in this case the angle of incidence of the ions varies across the surface. The 
variation of the etch yield across the surface has to be minimized and the interface roughness has to be equal for all angles between the ion beam and the curved substrate.

The ion beam parameters, which result in maximum reflectivity, i.e. low interface roughness, are determined on the basis of post-deposition analysis by near-normal-incidence reflectivity using $14.4 \mathrm{~nm}$ radiation and specular reflectivity of small-angle reflectivity measurements using $\mathrm{Cu} \mathrm{K} \mathrm{K}_{\alpha}$ radiation. To investigate the lateral distribution of the interface roughness, diffuse $\mathrm{x}$-ray scattering measurements are performed. The angular dependence of the etch yield is determined from the in situ reflectivity measurements, which are also used to control the thickness during deposition.

\section{EXPERIMENT}

\section{A. Multilayer production}

The Mo/Si multilayer structures are produced with $e$-beam evaporation in a dual chamber coating facility. The lower chamber is the evaporation chamber, which contains the electron gun (maximum power $6 \mathrm{~kW}$ ) and the materials to be evaporated. The pressure in the lower system during operation is $1 \times 10^{-7}$ mbar. The upper chamber contains a substrate holder, an ion gun, and the in situ reflectometer and operates at ultrahigh vacuum (UHV) conditions $\left(5 \times 10^{-9}\right.$ mbar). The entire deposition process is controlled by in-situ reflectivity measurements using $3.16 \mathrm{~nm}$ radiation at $13^{\circ}$ with respect to the surface. The in situ system enables monitoring of the $d$ spacing and the interface roughness during deposition as well as during ion bombardment. The deposition system has been described in detail in Ref. 15 .

These Mo/Si multilayers are being used for extreme ultraviolet lithography using $13.5 \mathrm{~nm}$ radiation. For these multilayers a $d$ spacing of $7.1 \mathrm{~nm}$ is required, in this case the required thicknesses of Mo is $2.4 \mathrm{~nm}$ and for $\mathrm{Si}$ is $4.7 \mathrm{~nm}$. In this study, 16-period $\mathrm{Mo} / \mathrm{Si}$ multilayers are produced using $\mathrm{Kr}^{+}$ion bombardment of the Si layers. An additional $3.8 \mathrm{~nm}$ thick Si layer is deposited on each Si layer, which is later removed by ion bombardment. The ion beam parameters investigated include energies between $300 \mathrm{eV}$ and $2 \mathrm{keV}$, and angles between $20^{\circ}$ and $50^{\circ}$ with respect to the substrate. The ion beam current was constant (19 mA) during all experiments. During deposition as well as during ion bombardment the substrate holder is rotated at $60 \mathrm{rpm}$. The entire fabrication process is controlled by continuous in situ X-ray reflectivity measurement. ${ }^{16,17}$

\section{B. Multilayer characterization}

In order to determine the interface roughness, both nearnormal-incidence reflectivity and small angle reflectivity are measured. The near-normal-incidence measurements are performed at $85^{\circ}$ with respect to the surface using wavelengths between 12.4 and $16.0 \mathrm{~nm}$. For these measurements a reflectometer at the Center for X-ray Optics is used. ${ }^{18}$ The smallangle reflectivity measurements are performed between $0^{\circ}$ and $5^{\circ}$ using $\mathrm{Cu} \mathrm{K}_{\alpha}$ radiation $(\lambda=0.154 \mathrm{~nm})$ at the Danish Space Research Institute. ${ }^{19}$

Diffuse x-ray scattering has been used to obtain insight in the lateral distribution of the interface roughness. For these measurements a triple axis setup with a $7.5 \mathrm{~kW}$ rotating $\mathrm{Cu}$ anode $(50 \mathrm{kV}, 150 \mathrm{~mA})$ is used at the Danish Space Research Institute. The detector is a $150 \mathrm{~mm}$ wide positionsensitive detector (2048 channels), which allows a wide detection angle $\left(\sim 8.5^{\circ}\right)$ with a resolution of $2.7 \mathrm{mdeg} / \mathrm{channel}$. This wide angle enables simultaneous detection of the specular beam and the diffuse $\mathrm{x}$-ray scattering up to the fourth Bragg maximum. The data for the diffuse $\mathrm{x}$-ray scattering is then extracted, which results in data corresponding to a scan parallel to the surface in reciprocal space. This will be referred to as transversal scans. ${ }^{19}$

\section{BASIC GROWTH EQUATIONS}

Before we discuss the experiments performed, an existing growth model is used, which is able to explain the roughening and smoothening processes during deposition and ion bombardment. Many models of the growth of single layers and multilayers have been suggested. ${ }^{12,13,20} \mathrm{We}$ follow the model in Ref. 11 with several small modifications. In this model the surface profile of a film at time $t$ is described by a function $h(x, y, t)$, where $h$ is the height at a certain position $(x, y)$. The surface profile $h(x, y, t)$ has a spatial frequency spectrum $h(q, t)$, and the model describes the evolution of $h(q, t)$ by roughening and smoothening processes in time.

These smoothening processes are considered to be viscous flow $(F)$ and surface diffusion $(D) .{ }^{14}$ The rate of change of the height is expressed by:

$$
\frac{d|h(q, t)|^{2}}{d t}=-\left(F q+D q^{4}\right)|h(q, t)|^{2} .
$$

The term $F q$ is the rate of relaxation by viscous flow, where

$$
F=\frac{\gamma}{\eta}
$$

and $(\gamma$ is the free energy and $\eta$ is the viscosity. The factor $D q^{4}$ is the rate of relaxation by surface diffusion, where

$$
D=\frac{2 D_{s} \gamma \Omega^{2} \nu}{k_{B} T},
$$

and $k_{B}$ is the Boltzmann constant, $T$ is the temperature, $D_{s}$ is the surface diffusion coefficient, $\Omega$ is the atomic volume, and $\nu$ is the number of atoms per unit surface.

Both diffusion and viscous flow are basically induced by the free energy $(\gamma)$. The difference between these two is found in the spatial frequency dependence: the relaxation by viscous flow has a $q$ dependence, and relaxation by diffusion has a $q^{4}$ dependence. This implies that relaxation by diffusion is effective for small features, while relaxation by viscous flow is effective for larger features.

In order to limit the number of fit parameters in the model, we determine which of the two smoothening terms dominates. Earlier, the process of ion bombardment has been described by a local increase of temperature. ${ }^{21}$ This study showed that in a small volume around the colliding ion, the temperature increases and the material is considered to behave like a liquid. Therefore, the Stokes-Einstein relation ( $\eta D=k_{B} T / 3 \pi L$, where $L$ is the diffusion length, which is considered to be equal to the nearest neighbor distance of Si: 
$0.234 \mathrm{~nm}$ ) can be used to compare the effect of diffusion to that of viscous flow. A spatial frequency $q^{*}$ can be defined at which the relaxation by viscous flow is equal to that of diffusion $\left[F q^{*}=D\left(q^{*}\right)^{4}\right]$. Using Eqs. (2), and (3), a value of $\Omega$ (the atomic volume for $\mathrm{Si}$ ) of $0.054 \mathrm{~nm}^{3}$, and $\nu=1.16 \times 10^{15} \mathrm{~cm}^{-3}$, the value $q^{*}=\left(3 \pi L / 2 \Omega^{2} \nu\right)^{1 / 3} \mathrm{~nm}^{-3}$ is determined to be $4 \mathrm{~nm}^{-1}$. $^{22}$ For values of $q$ smaller than $q^{*}$, the effect of viscous flow dominates over diffusion. The maximum spatial frequency that can be determined from diffuse $x$-ray scattering measurements is limited by the angle of reflection, and is in this case $0.2 \mathrm{~nm}^{-1}$ at the fourth order Bragg maximum. Physically, the upper limit is a value of $q \approx \pi / L$, the atomic dimension in reciprocal space, which for $\mathrm{Si}$ is determined to be $13 \mathrm{~nm}^{-1}$. This limit is close to the value where the smoothening effects of diffusion and viscous flow are calculated to be equal. From this, the general conclusion follows that viscous flow dominates over diffusion in the entire spatial frequency range investigated. These calculations show why in general only viscous flow has to be taken into account for modifications of a layer with ion bombardment, provided the ion energy is sufficiently high (above $100 \mathrm{eV}$ ). These general considerations show that the experiments performed earlier for $\mathrm{Mo} / \mathrm{Si}$ multilayer mirrors have in principle been unnecessary. ${ }^{13,23}$

Roughness of a surface can arise from two phenomena. The first is stochastic roughening, by material deposition or removal described by the term $\alpha$ in Eq. (4). This term is independent of spatial frequency and amplitude, which is why a Poisson-like process is assumed. The second process is described by the term $\left(K q^{2}\right) .^{24,25}$ which is the relaxation caused by ion bombardment, while $K$ is the etch flow. The roughening terms in the model of Ref. 12 are expressed by

$$
\frac{d|h(q, t)|^{2}}{d t}=\alpha+K q^{2}|h(q, t)|^{2} .
$$

The value of $K$ is dependent on the angle of incidence $\theta$ and the azimuth angle $\varphi$ of the ions with respect to the surface. Since the sample is rotated in the azimuth plane during ion bombardment as well as during deposition, $K$ is averaged over the azimuth angle. Therefore $K$ reduces to:

$$
K=\frac{a f}{\rho} Y_{0}(\theta),
$$

where $f$ is the ion flux, $a$ is the average penetration depth, $\rho$ is the density of atoms, and $Y_{0}(\theta)$ is the sputter yield averaged over the azimuth angle during rotation.

The power spectral density function (PSD) of the height variation of the surface is defined as $\operatorname{PSD}(q, t)$ $=\left\langle h(q, t), h^{*}(q, t)\right\rangle$. Combining both the roughening, Eq. (4), and smoothening terms, Eq. (1), results in a PSD function of a single layer:

$$
\begin{aligned}
P S D_{1}(q)= & \alpha \frac{\{1-\exp [-b(q) t]\}}{b(q)}+\exp \\
& {[-b(q) t] P S D_{\mathrm{sub}}(q), }
\end{aligned}
$$

where

$$
b(q)=F q-K q^{2},
$$

in which $b(q)$ represents the relaxation by viscous flow and by ion bombardment. The $\mathrm{PSD}_{1}$ is composed of contributions by the layer growth on an ideal smooth surface [the first term in Eq. (6)] and $P S D_{\text {sub }}$, the PSD of the substrate [part of the second term in Eq. (6)]. The latter is attenuated by a factor $\exp [-b(q) t]$. By using this equation recursively, the PSD of each layer of a multilayer can be determined. In a similar way the total PSD function consists of contributions by ion bombardment $\left(\mathrm{PSD}_{\mathrm{ion}}\right)$ and growth $\left(\mathrm{PSD}_{\mathrm{gr}}\right)^{26}$

$$
P S D(q)=P S D_{i o n}(q)+\exp \left[-b_{i o n}(q) . t\right] P S D_{g r}(q) .
$$

For the analysis of the data we thus have three fit parameters: $F_{\text {gr }}, F_{\text {ion }}$ and $K_{\text {ion }}$. It is obvious that $K_{\text {gr }}=0$, because during growth only stochastic roughening occurs. It is noted that no distinction is made between the growth of Si and Mo, implying that only average values are determined over the period of growth. Also Eq. (8) can be used recursively in order to determine the PSD of each layer of the multilayer. ${ }^{26}$ The PSD of the entire multilayer from the diffuse $x$-ray scattering measurements is further determined using the method described in Ref. 27. It is concluded that the model used in this study has only three parameters $\left(F_{\text {gr }}, F_{\text {ion }}\right.$ and $\left.K_{\text {ion }}\right)$, because the effect of diffusion is negligible compared to viscous flow.

\section{RESULTS AND DISCUSSION}

\section{A. Ion etch yield}

The etch yield determines whether the atoms are removed during ion bombardment or moved across the surface. In Sec. III it has been shown that moving atoms around, by diffusion or viscous flow, smoothens the layers while removing the atoms roughens the layers.

The frequency dependent roughening term, Eq. (5), is dependent on the etch yield, the penetration depth, and the flux of ions. From the in situ reflectivity measurements the etch yield is determined. In this experiment the additional thickness deposited is $3.8 \mathrm{~nm}$, and the time needed to remove this excess layer is measured. Separate experiments have been performed to determine the flux of the ions for all energies and angles of incidence by measuring the electrical current on a $1 \mathrm{~cm}^{2}$ probe on the position of the sample, while keeping the ion beam current constant $(19 \mathrm{~mA})$. The flux of ions decreases with the angle of incidence, which is a geometrical effect. The flux also decreases up to $30 \%$ going from $300 \mathrm{eV}$ to $2 \mathrm{keV}$, because of better defocusing properties at the higher ion beam voltage of the ion gun. This is consistent with the specifications of the ion gun.

The etch yield, normalized per incident ion, is displayed in Fig. 1 for several angles of incidence as a function of ion energy. The values are averaged over 10 periods. The graph shows that the etch yield increases with increasing ion energy and decreasing angle of incidence of the ions. For the fabrication of a multilayer on a curved substrate the additional layer thickness deposited has to vary over the surface to compensate the different etch rate due to variations of the etch angle. This additional layer can be calculated using the experimentally determined values for the etch yield and the 


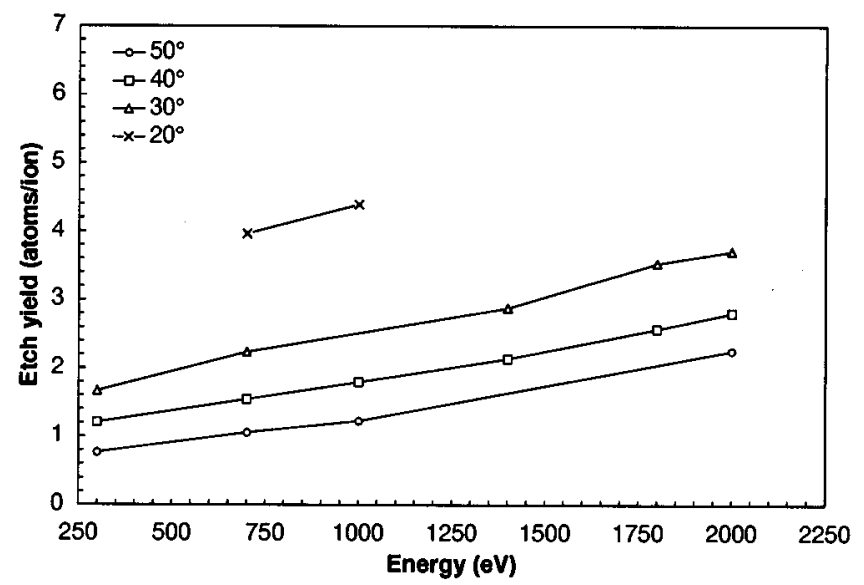

FIG. 1. The measured etch yield of Si atoms as a function of ion energy and angle of incidence.

geometry of the mirrors. In the experiments described in this study the substrates are flat. For the fabrication of multilayers on curved substrates the effect of redeposition could be different compared to flat substrates. This effect will have to be addressed in future experiments.

\section{B. Penetration depth}

If the penetration depth of the ions becomes comparable to the Si layer thickness, the ions might cause intermixing of Mo and Si. Therefore, the penetration depth and the lateral spread of collisions of the ions are calculated as a function of ion energy and angle using the TRIM-95 code. ${ }^{28}$ The average penetration depth of the ions in a Si layer is calculated to be less than $3.5 \mathrm{~nm}$ for all energies and angles of incidence. However, the maximum penetration depth could be as high as $6.5 \mathrm{~nm}$ for ions with an energy of $2 \mathrm{keV}$ at $50^{\circ}$ angle. The lateral spread of ions is determined to be equal to the penetration depth corrected for the geometrical effect of the angle of incidence. These calculations also yield the distributions of the $\mathrm{Si}$ and Mo atoms after bombardment. The fraction of intermixed atoms can be calculated using these distributions as well as the etch rate and the ion flux. In the case of $2 \mathrm{keV} \mathrm{Kr}^{+}$ions at $50^{\circ}$ angle of incidence, the fraction of $\mathrm{Si}$ atoms that penetrate into the Mo layer is found to be $5 \%$ at $0.2 \mathrm{~nm}$ from an ideal interface. The fraction of Mo into the Si layer is $8 \%$ at $0.2 \mathrm{~nm}$ at the reverse side of the interface. Because for all other ion energies and angles the penetration depth is less, the effect of intermixing can be neglected, on the scale of typical roughness values in all cases investigated.

\section{Growth parameters}

\section{Roughening effect}

First the frequency dependent roughening factor, $K$, is determined using in Eq. (5) the experimentally determined values for the etch yield and ion flux, and the calculated values for the penetration depth. The results are plotted in Fig. 2. The value of $K$ increases with increasing energy and angle of incidence. This indicates that with increasing energy

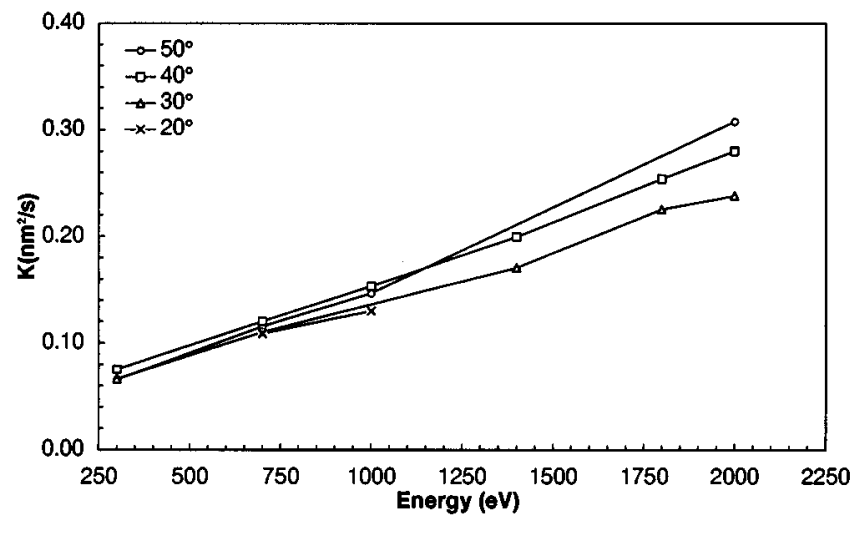

FIG. 2. Calculated values of $K$ using measured data on the etch yield and a calculated penetration depth.

and angle the roughness also increases, supposing that the smoothening terms for all energies and angles are equal. However, in the next section it will be shown that the smoothening terms are dependent on energy and angle.

It is noted that tabulated values for the atomic densities are used. In previous experiments however, we have observed a large free volume in the Si layer deposited at room temperature without ion bombardment. ${ }^{29} \mathrm{We}$ suggest that the free volume decreases during ion bombardment, in agreement to extended x-ray absorption fine structure experiments on similar samples. ${ }^{30}$ This implies that the accuracy of the value for the Si density is approximately $15 \%$, which also determines the accuracy of the value of $K$.

\section{Smoothening effect}

A few assumptions have been made in order to determine the values for the viscous flow $(F)$. It is assumed in Eq. (8) that during growth the time for viscous flow is limited to the time needed for deposition of one period plus excess layer, which is $360 \mathrm{~s}( \pm 10 \%)$ for all samples. The value for this viscous flow is considered to be constant for all samples deposited. During ion bombardment the time for viscous flow is limited to the time needed for removal of the excess layer. The values for the viscous flow have to be determined experimentally by fitting the diffuse x-ray scattering data of a modelled multilayer to the measured data. The input parameters for the model are the $d$ spacing, the thickness ratio of Mo and Si, the multilayer materials, and the PSD of each of the interfaces, as has been explained in Sec. III.

For the fit procedure for this type of measurement we use an existing method. ${ }^{25}$ The calculated diffuse x-ray scattering is then corrected for beam attenuation, and the measured reflectivity data is normalized to a constant sample volume. Fits to the measured diffuse x-ray scattering are only performed at the third order Bragg maximum, because of a higher accuracy than with the first and second order Bragg maxima. In Fig. 3 an example, of the transversal scan and the simulated diffuse $x$-ray scattering at the third order Bragg maximum of a sample $\left(2 \mathrm{keV}, 40^{\circ}\right)$ is plotted. From 


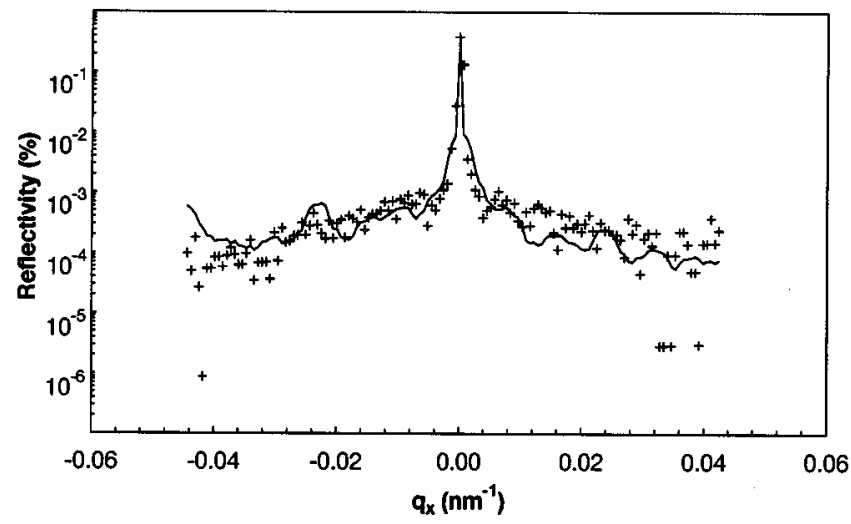

FIG. 3. The transversal scan at the third (+) Bragg maximum for the sample produced with $2 \mathrm{keV} \mathrm{Kr}^{+}$ions at $40^{\circ}$. The solid line represents the fit.

the graph it is concluded that the diffuse $\mathrm{x}$-ray scattering data of the modelled structures fit accurately to the measured data.

The value found for the viscous flow during growth is less than $0.03 \mathrm{~nm} / \mathrm{s}$ for all samples, which is negligibly small. In Fig. 4 the calculated values for the viscous flow during ion bombardment are shown. This clearly indicates that the smoothening effect by ion bombardment is increasing with ion energy and angle. This also indicates that probably even larger values for the viscous flow can be obtained for ion energies above $2 \mathrm{keV}$ and larger angles than $50^{\circ}$, both being currently the practical limits of the coating facility.

The value of $\alpha$, the stochastic roughening term, is also obtained from the fit, and is found to be $5 \times 10^{-6} \mathrm{~nm}^{4} / \mathrm{s}$. The value of $\alpha$ only scales the value of the diffuse x-ray scattering, because it has no frequency dependence.

\section{Correlation length}

From the transversal scan the correlation length of the interface roughness can also be determined using the method described in Ref 23. The correlation function used is a Lorentzian function. For all samples investigated a correla-

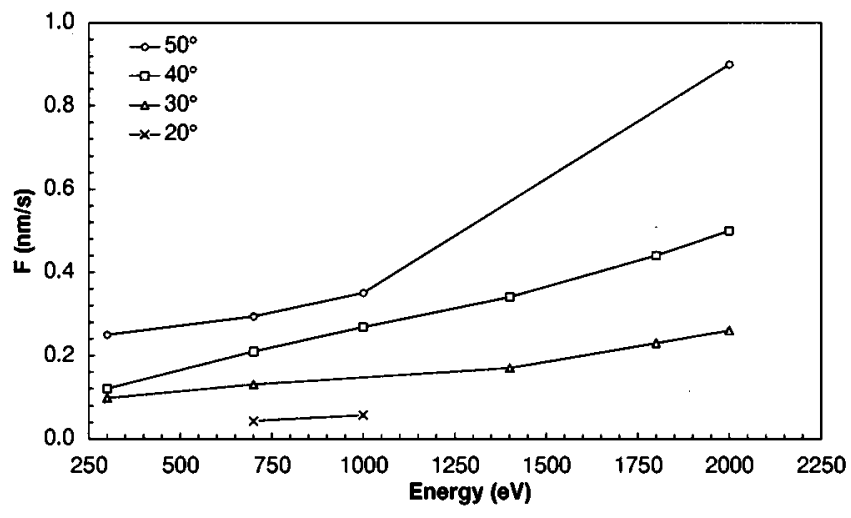

FIG. 4. The values of $F$ calculated from the diffuse x-ray scattering measurements.

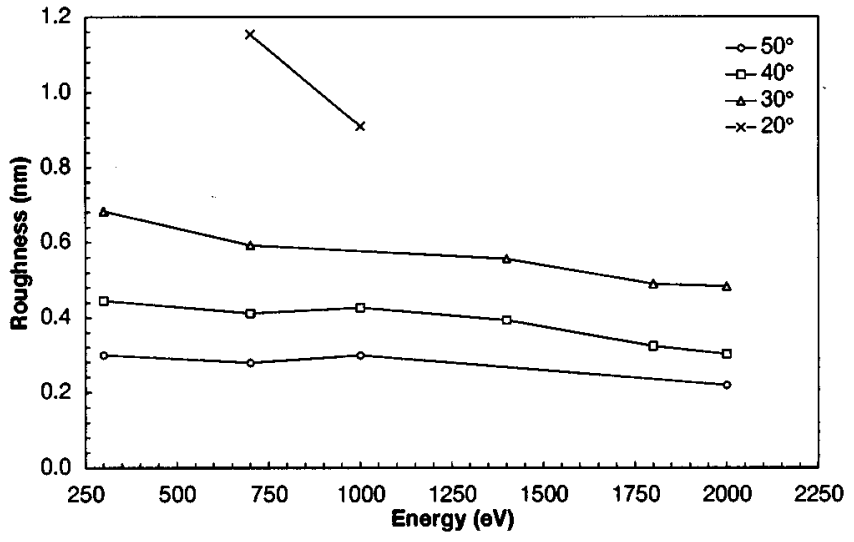

FIG. 5. The interface roughness determined from the specular reflectivity measurements with $\mathrm{Cu} \mathrm{K}_{\alpha}$ reflectivity measurements.

tion length of $50 \pm 10 \mathrm{~nm}$ is found. A distinction for the correlation length between the different ion beam parameters could not be obtained from the fit of the correlation function. More precise values might be obtained using high resolution diffuse $\mathrm{x}$-ray scattering ${ }^{31}$ or atomic force microscope (AFM) measurements.

\section{Interface roughness}

The different values for the sputter yield and the viscous flow result in differences in the interface roughness of the multilayers. These differences are determined from the specular reflectivity measurements using $\mathrm{Cu} \mathrm{K}_{\alpha}$ radiation, and are displayed in Fig. 5. The interface roughness decreases with increasing angle and ion energy. The effect of intermixing and the removal of atoms by ion bombardment is negligible compared to the smoothening effect by viscous flow.

The near-normal-incidence reflectivity measurements are plotted in Fig. 6. The minimum value of the interface roughness $(0.21 \mathrm{~nm})$ coincides with the maximum value measured for the near-normal-incidence reflectivity $\left(47 \%\right.$ at $85^{\circ}$ and

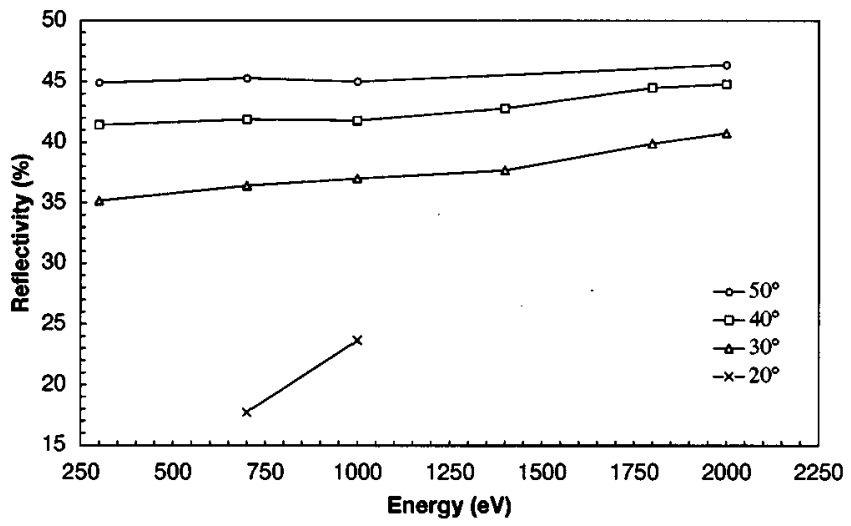

FIG. 6. The measured near-normal-incidence reflectivity at $87^{\circ}$ and $14.4 \mathrm{~nm}$ radiation. The values are corrected for small variations of the $d$ spacing. 
$\lambda=14.4 \mathrm{~nm}$ ) for the 16 -period $\mathrm{Mo} / \mathrm{Si}$ multilayers produced with ion bombardment at the optimal settings. These values coincide with the roughness values obtained from the $\mathrm{Cu} \mathrm{K}_{\alpha}$ reflectivity measurements.

\section{CONCLUSIONS}

$\mathrm{Mo} / \mathrm{Si}$ multilayer x-ray mirrors have been produced using $e$-beam evaporation and additional ion bombardment at ion energies between $300 \mathrm{eV}$ and $2 \mathrm{keV}$ and angles of incidence between $20^{\circ}$ and $50^{\circ}$ with respect to the surface. From near-normal-incidence reflectivity measurements it is concluded that the optimal ion beam parameters within this parameter range are $2 \mathrm{keV}$ and $50^{\circ}$ angle of incidence. These settings result in a minimum value of the interface roughness. From diffuse $\mathrm{x}$-ray scattering measurements it is concluded that the effect of viscous flow during ion bombardment dominates the change of the interface roughness, while the effect of intermixing as well as ion-induced sputtering are found to be negligible. The correlation length of the interface roughness is found to be $50 \mathrm{~nm}$, which indicates that the effect of viscous flow is larger than the lateral spread of collisions caused by the colliding ion. This lateral spread is almost equal to the penetration depth, which is several nanometers depending on the energy and angle of incidence.

For the production of multilayers on curved substrates, the values for the ion beam parameters described above are also optimal, because the angular dependence of the etch yield and the variation of the interface roughness is minimal in this case. For the production of multilayers on curved substrates also the effect of redeposition has to be taken into account. This might be different for flat and curved substrates, because of the different geometry.

\section{ACKNOWLEDGMENTS}

The authors acknowledge the use of the soft x-ray reflectometer made available by E.M. Gullikson (Center for X-ray Optics, Lawrence Berkeley Laboratory, Berkeley, CA). These investigations within the framework of FOM (the Foundation for Fundamental Research on Matter) are supported by STW (the Netherlands Technology Foundation) and the Dutch Government in the context of EUREKA.

${ }^{1}$ K. Murakami, H. Nakamura, T. Oshino, M. Ohtani, and H. Nagata, Proc. SPIE 1742, 614 (1992).
${ }^{2}$ M. Cevro and G. Carter, Opt. Eng. (Bellingham) 34, 596 (1995).

${ }^{3}$ E. Spiller, Appl. Phys. Lett. 54, 2293 (1989).

${ }^{4}$ E. J. Puik, M. J. van der Wiel, J. Verhoeven, and H. Zeijlemaker, Thin Solid Films 193/194, 782 (1990).

${ }^{5}$ E. Louis, E. Spiller, S. Abdali, F. E. Christensen, H.-J. Voorma, N. B. Koster, P. K. Frederiksen, C. Tarrio, E. M. Gulikson, and F. Bijkerk, Proc. SPIE 2515, 194 (1995).

${ }^{6}$ R. Schlatmann, C. Lu, J. Verhoeven, E. J. Puik, and M. J. van der Wiel, OSA Tech. Dig. Ser. 7, PD6-1 (1992).

${ }^{7}$ R. Schlatmann, A. Keppel, Y. Xue, and J. Verhoeven, Appl. Phys. Lett. 63, 3297 (1993).

${ }^{8}$ R. Schlatmann, J. Verhoeven, L. Chunguang, E. J. Puik, and M. J. van der Wiel, Appl. Surf. Sci. 78, 147 (1994).

${ }^{9}$ L. G. Parratt, Phys. Rev. 95, 359 (1954).

${ }^{10}$ J. Verhoeven, L. Chunguang, E. J. Puik, M. J. van der Wiel, and T. P. Huijgens, Appl. Surf. Sci. 55, 97 (1992).

${ }^{11}$ M. Niibe, M. Hayashida, T. Iizuka, A. Miyake, Y. Watanabe, R. Takahsi, and Y. Fukuda, Proc. SPIE 1343, 2 (1990).

${ }^{12}$ E. Chason, T. M. Mayer, B. K. Kellerman, D. T. McIlroy, and A. J. Howard, Phys. Rev. Lett. 72, 3040 (1994).

${ }^{13}$ D. G. Stearns, Appl. Phys. Lett. 62, 1745 (1993).

${ }^{14}$ T. M. Mayer, E. Chason, and A. J. Howard, J. Appl. Phys. 76, 1633 (1994).

${ }^{15}$ E. Louis, H.-J. Voorma, N. B. Koster, L. Shmaenok, F. Bijkerk, R. Schlatmann, J. Verhoeven, Yu. Ya. Platonov, G. E. van Dorssen, and H. Padmore, Microelectron. Eng. 23, 215 (1994).

${ }^{16}$ E. J. Puik, M. J. van der Wiel, H. Zeijlemaker, and J. Verhoeven, Appl. Surf. Sci. 47, 63 (1991).

${ }^{17}$ E. Spiller, Soft X-Ray Optics (SPIE, Bellingham, WA, 1994).

${ }^{18}$ E. M. Gullikson, J. H. Underwood, P. C. Baston, and V. Nikitin, J. X-Ray Sci. Technol. 3, 283 (1992).

${ }^{19}$ F. E. Christensen, A. Hornstrup, E. Jakobsen, P. Jonasson, M. M. Madsen, H. W. Schnopper, N. J. Westergaard, and P. Orup, Nucl. Instrum. Methods Phys. Res. A 256, 381 (1987).

${ }^{20}$ W. W. Mullins, J. Appl. Phys. 30, 77 (1959).

${ }^{21}$ C. Volkert and A. Polman, Mater. Res. Soc. Symp. Proc. 235, 3 (1992).

${ }^{22}$ O. B. Loopstra, E. R. van Snek, Th. H. de Keijser, and E. J. Mittemeijer, Phys. Rev. B 15, 44 (1991).

${ }^{23}$ R. Schlattman, J. D. Schindler, and J. Verhoeven, Phys. Rev. B 54, 10880 (1996).

${ }^{24}$ R. M. Bradley and J. M. E. Harper, J. Vac. Sci. Technol. A 6, 2390 (1988).

${ }^{25}$ P. Sigmund, Phys. Rev. 184, 383 (1969).

${ }^{26}$ E. Spiller, D. G. Stearns, and M. Kumrey, J. Appl. Phys. 74, 107 (1993).

${ }^{27}$ D. G. Stearns, J. Appl. Phys. 71, 4288 (1992).

${ }^{28}$ J. F. Ziegler, The Stopping Range of Ions in Matter (Pergamon, New York, 1985), Vol. 2-6.

${ }^{29}$ H.-J. Voorma, E. Louis, N. B. Koster, and F. Bijkerk, J. Appl. Phys. (submitted).

${ }^{30}$ H.-J. Voorma, G. E. van Dorssen, E. Louis, N. B. Koster, A. D. Smith, M. D. Roper, and F. Bijkerk, Appl. Surf. Sci. 93, 221 (1996).

${ }^{31}$ F. E. Christensen, S. Abdali, A. Hornstrup, H. W. Shnopper, P. Slane, and S. E. Romaine, Proc. SPIE 2011, 18 (1994). 